Revta brasil. Bot., São Paulo, V.23, n.2, p.161-167, jun. 2000

\title{
Análise ultra-estrutural de folhas de três espécies de Solanaceae após inoculação com o vírus da necrose branca do tomateiro (VNBT - Tymovirus)
}

\author{
FRANCISCO ANDRÉ OSSAMU TANAKA ${ }^{1,3}$, SÍLVIA RODRIGUES MACHADO ${ }^{1}$ \\ e MARIA MÉRCIA BARRADAS ${ }^{2}$
}

(recebido em 23 de junho de 1999; aceito em 5 de janeiro de 2000)

\begin{abstract}
Ultrastructural analysis of leaves from three species of Solanaceae after inoculation with the tomato white necrosis virus (TWNV - Tymovirus)). The leaf ultrastructure of Nicotiana glutinosa L., Lycopersicon pimpinellifolium L., and Physalis angulata L. inoculated with the tomato white necrosis virus (TWNV - Tymovirus) was analysed. Plants were kept in a greenhouse at $25^{\circ} \mathrm{C}$ and inoculated with the virus when tree to four leaves were totally developed. Fifteen days after inoculation, samples were collected from the median third of the $3^{\text {rd }}$ or $4^{\text {th }}$ leaf from the apex. The samples were prepared for analysis using conventional transmission electron microscope techniques. The ultrastructural analysis of the chlorenquima cells showed vesiculation and vacuolation of the chloroplasts and mitochondria, presence of multivesicular bodies, and a slight dilation of the plasmodesmata in N. glutinosa and L. pimpinellifolium. In these two species, virus-like particles were seen in the cytoplasm and vacuoles. P. angulata plants did not show subcellular alterations. Macroscopic observations, retroinoculation tests, and ultrastructural analysis showed the presence of local and systemic symptoms in N. glutinosa, latency in L. pimpinellifolium, and immunity in P. angulata.
\end{abstract}

RESUMO - (Análise ultra-estrutural de folhas de três espécies de Solanaceae após inoculação com o vírus da necrose branca do tomateiro (VNBT - tymovirus)). Foi estudada a ultra-estrutura foliar das solanáceas Nicotiana glutinosa L., Lycopersicon pimpinellifolium L. e Physalis angulata L. inoculadas com o vírus da necrose branca do tomateiro (VNBT - Tymovirus). As plantas mantidas em casa-de-vegetação com temperatura constante de $25{ }^{\circ} \mathrm{C}$ foram inoculadas quando apresentavam três a quatro folhas totalmente expandidas. Quinze dias após a inoculação, foram coletadas amostras do terço médio do limbo da $3^{\mathrm{a}}$ ou da $4^{\mathrm{a}}$ folha a partir do ápice. As amostras foram preparadas para análise em microscopia eletrônica de transmissão segundo técnicas convencionais. A análise ultra-estrutural das células do clorênquima revelou principalmente vesiculação e vacuolação dos cloroplastos e de mitocôndrias, além da ocorrência de corpos multivesiculares e ligeira dilatação dos plasmodesmos em $N$. glutinosa e L. pimpinellifolium. Nestas duas espécies foram observadas "virus-like-particles" no citoplasma e nos vacúolos. Plantas de P. angulata não mostraram alterações de ultra-estrutura. As observações macroscópicas, os testes de retroinoculação e as análises ultra-estruturais revelaram sintomas locais e sistêmicos em $N$. glutinosa, latência em L. pimpinellifolium e imunidade em P. angulata.

Key words - Tymovirus, TWNV, Solanaceae, leaf, ultrastructure

\section{Introdução}

O vírus da necrose branca do tomateiro (VNBT) foi constatado inicialmente em Itaquaquecetuba-SP, em um cultivo comercial de tomateiro por Chagas et al. (1975), causando sintoma diferente dos até então conhecidos, relacionados aos vírus desta cultura. Tais sintomas eram manchas necróticas brancas. Desde então, este vírus vem sendo estudado no Centro de Sanidade Vegetal do Instituto Biológico, em São Paulo.

1. Departamento de Botânica, Instituto de Biociências, Universidade Estadual Paulista, Caixa Postal 510, 18618-000 Botucatu, SP, Brasil.

2. Centro de Sanidade Vegetal, Instituto Biológico, Av. Conselheiro Rodrigues Alves, 1252, Vila Mariana 04014-002 São Paulo, SP, Brasil.

3. Autor para correspondência: botanica@ibb.unesp.br
Barradas (1983) caracterizou o VNBT do ponto de vista químico, biológico, sorológico e fisicoquímico, como um novo isolado do vírus do mosaico da berinjela ("eggplant mosaic virus" - EMV Tymovirus), o primeiro vírus deste gênero a ser descrito no Brasil. Os vírus do gênero Tymovirus têm como características, partículas isométricas de aproximadamente $30 \mathrm{~nm}$, genoma de RNA simples e ausência de envelope protetor. A análise destes vírus através de microscopia eletrônica, tanto de material purificado como "leaf-dip", mostra partículas cheias e vazias. Os principais vetores para sua disseminação, na natureza, são os coleópteros (Koenig \& Lesemann 1979, Matthews 1991, Murphy et al. 1995). A alteração citológica típica causada pelos vírus pertencentes a este gênero consiste na invaginação da membrana interna dos cloroplastos e vesiculações das mitocôndrias (Barradas 1983, Matthews 1991, Alexandre 1997). 
Com o objetivo de ampliar o conhecimento sobre as alterações celulares causadas pelo VNBT em outras espécies de Solanaceae, neste trabalho, foi analisada comparativamente a ultra-estrutura foliar de plantas de Nicotiana glutinosa L., Lycopersicon pimpinellifolium L. e Physalis angulata L. sadias e após a inoculação com o VNBT. Estas três espécies são referidas como suscetíveis ao VNBT (Barradas 1983).

\section{Material e métodos}

O inóculo inicial foi obtido da viroteca do Laboratório de Estudos de Vetores do Centro de Sanidade Vegetal do Instituto Biológico de São Paulo, onde fragmentos foliares contendo o vírus são mantidos desidratados em $\mathrm{CaCl}_{2}$ (Barradas \& Silberschmidt 1973, Barradas 1978, 1992).

As sementes de N. glutinosa foram obtidas através do estoque de uso em rotina do CSV do Instituto Biológico de São Paulo, as de L. pimpinellifolium cedidas pelo Prof. Dr. Chukichi Kurozawa, do Departamento de Defesa Fitossanitária da Faculdade de Ciências Agronômicas de Botucatu (SP) e as sementes de $P$. angulata coletadas da vegetação espontânea no Município de Mirandópolis (SP). As plantas foram transplantadas para vasos e mantidas em casa-de-vegetação com temperatura controlada a $25{ }^{\circ} \mathrm{C}$ até atingirem o estágio ideal para inoculação, que era a presença de três a quatro folhas totalmente expandidas.

O inóculo foi obtido através de plantas de Datura stramonium ou N. glutinosa utilizadas para multiplicação do VNBT as quais apresentavam sintomas sistêmicos bem evidentes, principalmente o mosaico. O extrato foi confeccionado utilizando-se sulfito de sódio a $0,5 \%$, triturando-se as folhas com sintomas. O inóculo foi friccionado na $2^{\mathrm{a}}$ ou $3^{\mathrm{a}}$ folha a partir do ápice, de cada planta, com o próprio pistilo. As plantas-controle foram tratadas apenas com o sulfito de sódio a $0,5 \%$ e mantidas a uma distância de aproximadamente $1,5 \mathrm{~m}$ das plantas inoculadas. Para a observação dos sintomas e coleta dos dados foram inoculadas 20 plantas de cada espécie.

Os testes de recuperação foram realizados em plantas de $D$. stramonium e N. glutinosa, as quais, segundo Barradas (1983), são suscetíveis ao VNBT e reagem com sintomas locais e sistêmi$\cos$.

A coleta de amostras foi realizada 15 dias após a inoculação com o VNBT, quando as plantas suscetíveis já mostravam sintomas sistêmicos. Amostras do limbo de folhas totalmente expandidas, do $3^{\circ}$ ou $4^{\circ}$ nó, foram fixadas em solução de glutaraldeído a 2,5\% em tampão fosfato $0,1 \mathrm{M}, \mathrm{pH} 7,3$, pós-fixadas em tetróxido de ósmio a $1 \%$ no mesmo tampão, desidratadas em série cetônica e incluídas em araldite. Os cortes ultrafinos foram contrastados com acetato de uranila e citrato de chumbo (Reynolds 1963) e observados ao microscópio eletrônico de transmissão Philips EM 100 , em $80 \mathrm{kV}$.

\section{Resultados}

Plantas de $N$. glutinosa reagiram com lesões locais, evidenciadas como pontos necróticos, 4-5 dias após a inoculação, e início de sintomas sistêmicos do tipo clareamento de nervuras e mosaico, 6-7 dias após a inoculação. Até este período, L. pimpinellifolium e $P$. angulata não manifestaram sintomas; no entanto, o resultado do teste de retroinoculação foi positivo em $L$. pimpinellifolium e negativo em $P$. angulata, revelando que o VNBT não estava presente nestas plantas.

As células do clorênquima de folhas sadias de $N$. glutinosa, (figuras 1 e 2), L. pimpinellifolium (figura 7) e $P$. angulata (figura 11) mostram cloroplastos lentiformes distribuídos regularmente no citoplasma periférico, com grãos-de-amido proeminentes e grânulos osmiofílicos, além de tilacóides íntegros e grana de distribuição esparsa no estroma. Mitocôndrias e peroxissomos com matriz elétron-densa foram observados nas adjacências dos cloroplastos. O núcleo, de posição periférica e com nucléolo conspícuo, é bem evidente em algumas células. Na parede celular, plasmodesmos são freqüentemente observados nas três espécies.

Folhas de $N$. glutinosa infectadas (figuras 3-6) apresentam cloroplastos ligeiramente intumescidos em relação aos da planta sadia, mais arredondados e, em geral, aglomerados nos pólos das células em paliçada (figura 3). A membrana interna do envelope plastidial apresenta invaginações formando vesículas que crescem e se rompem, liberando conteúdo membranoso; freqüentemente, a membrana destas vesículas funde-se ao tonoplasto e o seu conteúdo é incorporado pelo vacúolo; os tilacóides tornam-se dilatados e ocorre uma aparente diminuição dos grana, que são comprimidos pela intensa vacuolação da membrana interna do cloroplasto (figuras 4 e 5). As mitocôndrias localizadas nas adjacências das regiões vesiculadas dos cloroplastos também mostram vesículas na matriz, oriundas provavelmente da dilatação das cristas mitocondriais (figura 6). Corpos multivesiculares associados ao tonoplasto e inclusões elétron-densas no interior dos cloroplastos, distintas dos plastoglóbulos, são visíveis nestas células. Grumos elétron-densos dispersos no citoplasma, identificados como 'virus-like particles' (VLP), são também observados (figuras 3 e 4). 


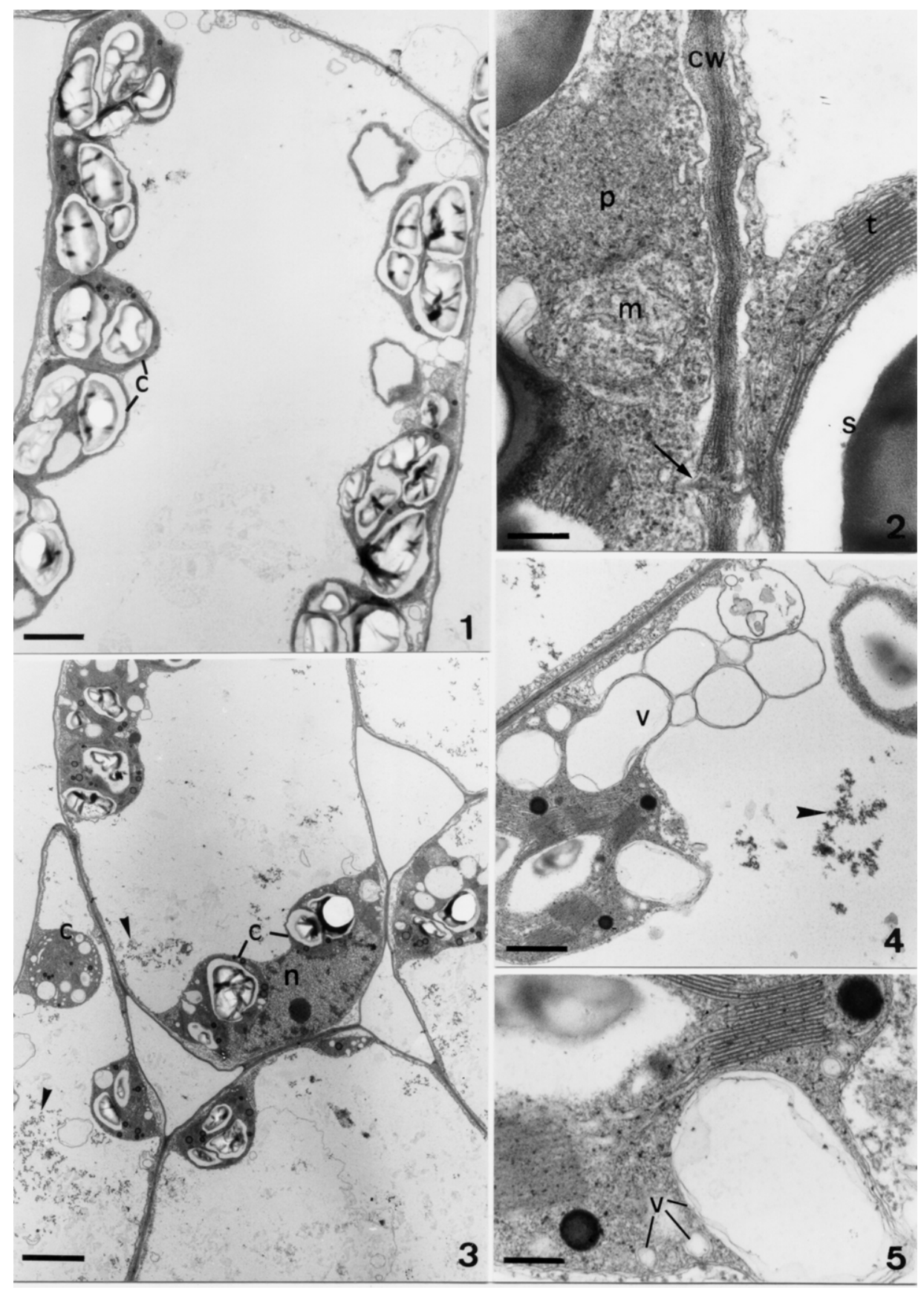

Figuras 1-5. Nicotiana glutinosa L. 1 e 2. Planta-controle. 1. Célula do clorênquima apresentando cloroplastos (c) com grãos-de-amido conspícuos distribuídos regularmente no citoplasma periférico. Escala $=2,3 \mu \mathrm{m}$. 2. Parte da célula mostrando mitocôndria $(\mathrm{m})$, peroxissomo (p), cloroplastos com grãos-de-amido (s) e tilacóides (t) íntegros; parede celular (cw) com plasmodesmo (seta). 3-5. Plantas infectadas. Escala $=0,24 \mu \mathrm{m}$. 3. Células do clorênquima mostrando os cloroplastos (c) intumescidos e aglomerados; as pontas de seta indicam "virus-like particles" (VLP); n, núcleo. Escala = 3,1 $\mu \mathrm{m}$. 4. Cloroplastos (c) com vesículas (v); a ponta de seta indica VLP. Escala $=0,75 \mu \mathrm{m}$. 5. Detalhe do cloroplasto mostrando vesículas (V) de dupla membrana. Escala $=0,24 \mu \mathrm{m}$. 


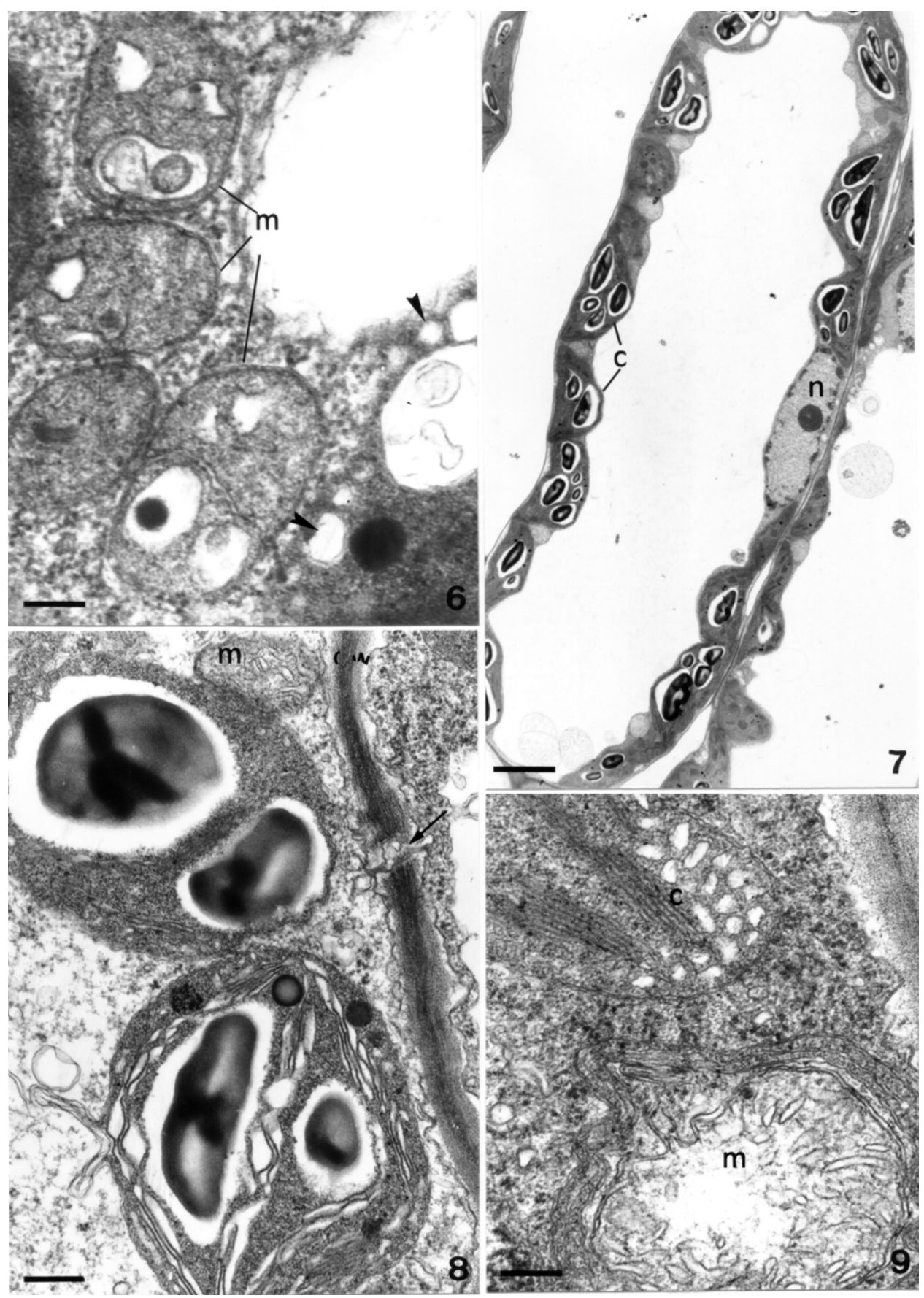

Figuras 6-9. Nicotiana glutinosa L. Planta infectada mostrando mitocôndrias (m) vesiculadas próximas ao cloroplasto vesiculado (pontas de seta). Escala $=0,17 \mu \mathrm{m}$. Figuras 7-9. Lycopersicon pimpinellifolium L. 7. Planta-controle. Células do clorênquima mostrando cloroplastos (c) distribuídos regularmente no citoplasma periférico; n, núcleo. Escala = 3,1 $\mu \mathrm{m}$. 8 e 9. Plantas infectadas. 8. Cloroplastos com tilacóides intumescidos e dilatados. A seta indica plasmodesmo ligeiramente dilatado. Escala =0,32 $\mu \mathrm{m}$. 9. Mitocôndria intumescida com cristas dilatadas próxima ao cloroplasto vesiculado. Escala $=0,17 \mu \mathrm{m}$. 
Em L. pimpinellifolium, além das alterações descritas para $N$. glutinosa, ocorre um forte intumescimento dos tilacóides e surgimento de inúmeras vesículas dispersas no estroma dos cloroplastos (figuras 8 e 9). Estes apresentam-se agrupados nos pólos das células em paliçada. As mitocôndrias mostram cristas mais proeminentes e aparentemente dilatadas em relação às das plantas sadias, além de zonas elétron-transparentes (figura 9). A membrana plasmática e o tonoplasto mostram contorno fortemente sinuoso; vesículas e material membranoso são visíveis dispersos no citoplasma e no interior dos vacúolos, além de corpos multivesiculares associados à membrana plasmática (figura 10). Os plasmodesmos estão aparentemente mais dilatados em relação aos das plantas sadias (figura 8).

Em $P$. angulata, os cloroplastos e as mitocôndrias das células do clorênquima de plantas inoculadas não mostram alterações (figuras 12 e 13); os plasmodesmos também são semelhantes aos das células de plantas sadias.

\section{Discussão}

A manifestação de sintomas como clareamento das nervuras e mosaico, em $N$. glutinosa, $L$. pimpinellifolium e $P$. angulata, causada pela infecção induzida pelo VNBT, foi relatada por Barradas (1983), ao redor de 5-7 dias após a inoculação com o vírus. No entanto, no presente trabalho não se verificou tal fato em $L$. pimpinellifolium e $P$. angulata, mesmo 15 dias após a inoculação. A ausência de sintomas nas plantas destas duas espécies provavelmente deve-se ao fato de que as mesmas pertencem a populações diferentes daquelas utilizadas por Barradas (1983), podendo então, reagir de maneiras distintas. Tal sugestão fundamentase nos trabalhos de Colariccio et al. (1982, 1984). Testando o efeito do VNBT em diferentes cultivares de Lycopersicon esculentum Mill., em casa-de-vegetação a $25^{\circ} \mathrm{C}$ e em condições de campo, esses autores observaram que cada cultivar comportou-se de maneira distinta à infecção viral.

Quanto à ultra-estrutura, a principal alteração observada em $N$. glutinosa e L. pimpinellifolium, foi a vesiculação dos cloroplastos, como já descrito para vírus pertencentes ao grupo Tymovirus (Ushiyama \& Matthews 1970, Moline 1973, Koenig \& Lesemann
1979, Barradas 1983, Matthews 1991), além de deformação e aglomeração destas organelas. Os grana são comprimidos pelas vesículas, fato este já observado por Ushiyama \& Matthews (1970) em plantas de nabo chinês (Brassica pekinensis). As vesículas dos cloroplastos funcionam como provável sítio de replicação viral, acumulando as proteínas virais, assim como acontece no núcleo (Hatta \& Matthews 1976, Matthews 1991). As vesículas formadas pela invaginação da membrana interna dos cloroplastos formam vacúolos no seu interior e, após o rompimento, liberam um conteúdo membranoso para o citoplasma, fato este também constatado em Petunia hybrida infectada por um Tymovirus diferente do VNBT (Alexandre 1997).

Além de alterações nos cloroplastos, nestas duas espécies foram observadas vesiculações nas mitocôndrias. Tal alteração foi também descrita por Barradas (1983) em D. stramonium inoculada com o VNBT e por Alexandre (1997), em plantas de Petunia hybrida naturalmente infectadas por um novo isolado do EMV encontrado no Brasil.

Em plantas de $P$. angulata inoculadas, os cloroplastos e as mitocôndrias mostraram organização similar à de plantas sadias.

A presença de VLP nos vacúolos das células do clorênquima, constatada em $N$. glutinosa infectada com o VNBT, foi também observada por diversos autores em diferentes espécies vegetais (Hatta \& Matthews 1976, Lesemann 1977, Barradas 1983, Matthews 1991).

Em L. pimpinellifolium, além das alterações acima constatadas, a aparente dilatação dos plasmodesmos pode estar relacionada com a passagem do vírus célula-a-célula, como sugeriu Rivas (1996), estudando o vírus X da batata ("potato virus X" Potexvirus) em plantas da família Amaranthaceae.

A ocorrência de corpos multivesiculares no citoplasma periférico tem sido comumente associada à reciclagem de membranas (Alberts et al. 1994); contudo, em plantas infectadas por vírus não há referência, na literatura consultada, sobre a possível função destas estruturas.

Nas condições deste trabalho, as observações macroscópicas, os testes de retroinoculação e as análises ultra-estruturais revelaram que $N$. glutinosa é suscetível ao VNBT, L. pimpinellifolium é hospedeira latente e $P$. angulata é imune. 


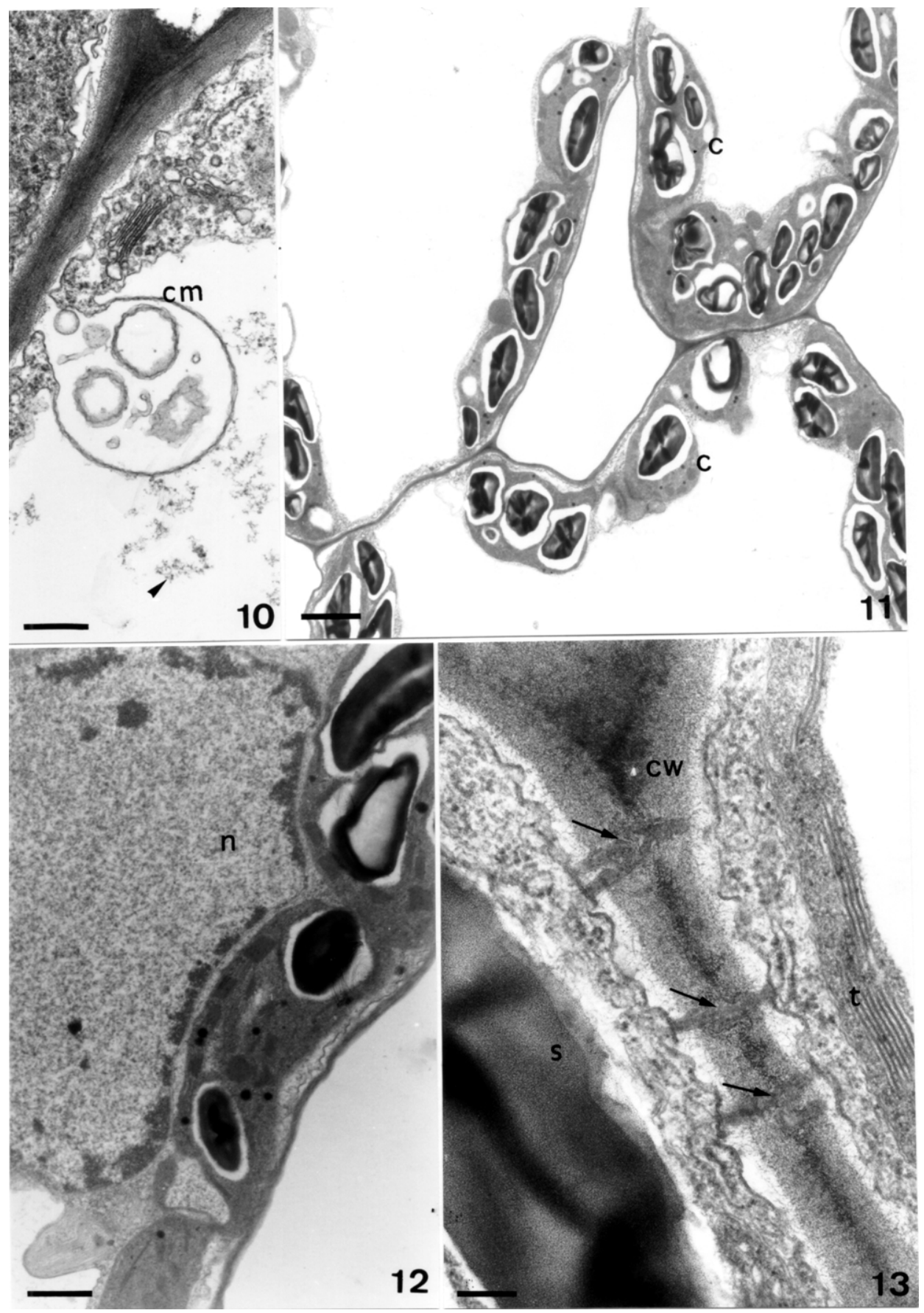

Figuras 10-13. 10. Lycopersicon pimpinellifolium L: Planta infectada mostrando célula com corpo multivesicular $(\mathrm{cm})$ associado à membrana plasmática; a ponta de seta indica "virus-like particles" (VLP). Escala = 0,32 $\mu \mathrm{m} .11-13$. Physalis angulata L. 11. Planta-controle. Células do clorênquima mostrando cloroplastos (c) com grãos-de-amido proeminentes distribuídos regularmente no citoplasma periférico. Escala = 2,3 $\mu \mathrm{m} .12$ e 13. Plantas infectadas. 12. Cloroplastos (c) íntegros no citoplasma periférico; n, núcleo. Escala $=1,3 \mu \mathrm{m}$. 13. Parede celular (cw) com plasmodesmos (setas) íntegros. Os cloroplastos (c) mostram tilacóides (t) sem alterações; s, grãos-de-amido. Escala $=0,17 \mu \mathrm{m}$. 
Agradecimentos - À FAPESP pela bolsa concedida ao primeiro autor (Proc. 96/3102-01); ao Prof. Dr. Chukichi Kurozawa, do Departamento de Defesa Fitossanitária, Faculdade de Ciências Agronômicas Botucatu (SP), pelo fornecimento de sementes de Lycopersicon pimpinellifolium; ao Centro de Microscopia Eletrônica, Instituto de Biociências, da UNESP - Câmpus de Botucatu-SP, onde este trabalho foi realizado, pela assistência técnica e ao Prof. Dr. João Semir do Departamento de Botânica da Universidade Estadual de Campinas - UNICAMP pela identificação da espécie Physalis angulata.

\section{Referências bibliográficas}

ALBERTS, B., BRAY, D., LEWIS, J., RAFF, M., ROBERTS, K. \& WATSON, J.D. 1994. Molecular biology of the cell. $3 \mathrm{ed}$. Garland Publishing Inc, New York.

ALEXANDRE, M.A.V. 1997. Identificação de um Tymovirus isolado de Petunia $x$ hybrida Vilm. Tese de doutorado, Universidade de São Paulo, São Paulo.

BARRADAS, M.M. 1978. Organização de uma coleção de vírus fitopatogênicos em tecidos foliares desidratados com cloreto de cálcio. O Biológico 44:221-229.

BARRADAS, M.M. 1983. Caracterização do vírus da necrose branca do tomateiro (VNBT) e sua identificação como um Tymovirus. Tese de doutorado, Universidade de São Paulo, São Paulo.

BARRADAS, M.M. 1992. IB mantém coleção de fitovírus. Comunicação da Pesquisa Agropecuária. 10:9.

BARRADAS, M.M. \& SILBERSCHMIDT, K.M. 1973. Conservação de vírus vegetais em tecidos secos de folhas. Arquivos do Instituto Biológico 40:375-379.

CHAGAS, C.M., VICENTE, M. \& JULY, J.R. 1975. Morfologia e características de um vírus causando necrose branca em tomateiro. Arquivos do Instituto Biológico 42:157-162.
COLARICCIO, A., BARRADAS, M.M., VICENTE, M. \& OLIVEIRA, D.A. 1982. Efeito da infecção pelo vírus da necrose branca do tomateiro (VNBT) em cinco cultivares de Lycopersicon esculentum Mill. I - Experimentos em casade-vegetação, à temperatura constante. Arquivos do Instituto Biológico 49:56-65.

COLARICCIO, A., BARRADAS, M.M. \& VICENTE, M. 1984. Efeito da infecção pelo vírus da necrose branca do tomateiro (VNBT) em cinco cultivares de Lycopersicon esculentum Mill. - II - Experimento em condições de campo. Arquivos do Instituto Biológico 51:17-22.

HATTA, T. \& MATTHEWS, R.E.F. 1976. Sites of coat protein accumulation in turnip yellow mosaic virus infected cells. Virology 73:1-16.

KOENIG, R. \& LESEMANN, D.E. 1979. Tymovirus Group, Descriptions of Plant Viruses. C.M.I./A.A.B. no. 214

LESEMANN, D.E. 1977. Virus group-specific and virus-specific cythological alterations induced by members of the Tymovirus group. Phytopathologische Zeitschrift 90:315-336.

MATTHEWS, R.E.F. 1991. Plant Virology. 3 ed. Academic Press Inc., San Diego, California.

MOLINE, H.E. 1973. Ultrastructure of Datura stramonium leaves infected with the Physalis mottle strain of Belladona mottle virus. Virology 56:123-133.

MURPHY, F.A., FAUQUET, C.M., BISHOP, D.H.L., GHABRIAL, S.A., JARVIS, A.W., MARTELLI, G.P., MAYO, M.A. \& SUMMERS, M.D. 1995. Virus Taxonomy. Sixth Report of the International Committee on Taxonomy of Viruses. Archives of Virology (Supplement 10): $1-586$

REYNOLDS, E.S. 1963. The use of lead citrate at high $\mathrm{pH}$ as an eletron-opaque stain in electron microscopy. Journal of Cell Biology 17:208.

RIVAS, E.B. 1996. Comportamento do vírus $\mathrm{X}$ da batata, anatomia e ultra-estrutura em espécies $\mathrm{C}_{4}$ e $\mathrm{C}_{3}-\mathrm{C}_{4}$ de Amaranthus e Alternanthera (Amaranthaceae). Dissertação de mestrado, Universidade de São Paulo, São Paulo.

USHIYAMA, R. \& MATTHEWS, R.E.F. 1970. The significance of chloroplast abnormalities associated with infection by turnip yellow mosaic virus. Virology 42:293-303. 